\title{
South African Guidelines Excellence (SAGE): Efficient, effective and unbiased clinical practice guideline teams
}

There is increasing worldwide interest in clinical practice guidelines (CPGs). A range of different evidence-based methods for CPG activities have been established (e.g. Schünemann et al., ${ }^{[1]}$ Brouwers et al., ${ }^{[2]}$ Brouwers et al. ${ }^{[3]}$ Hillier et al. ${ }^{[4]}$ and Guyatt et al. $\left.{ }^{[5]}\right)$, and there is common agreement in these that poorly conceived CPG team composition and management can jeopardise CPG integrity. Recognised CPG initiatives such as the Scottish Intercollegiate Guideline Network (SIGN) (http:// www.sign.ac.uk) and the National Institute of Health and Care Excellence (NICE) (https://www.nice.org.uk/guidance) therefore provide guidance on CPG team construction and management. This editorial is the third in a series produced by the South African Guidelines Excellence (SAGE) team. Project SAGE is funded by a South African Medical Research Council Flagship Grant (2014 - 2017). In our two previous editorials we discussed the critical components of a good-quality $\mathrm{CPG}^{[6]}$ and the work being undertaken by Project SAGE to explore and better understand the development, implementation and use of CPGs in the South African (SA) primary care setting. ${ }^{[7]}$ In this editorial we outline steps for effective, efficient and outcome-focused CPG team membership, roles and management.

1. Determine responsibilities and tasks. CPG team members may be asked to undertake a range of tasks. Efficient and effective CPG teams usually include methodologists (e.g. clinical epidemiologists, librarians, technical writers) who collate the evidence base, and experts who interpret the evidence base within local contexts. Team training requirements regarding best-practice CPG processes need to be identified and addressed prior to CPG commencement, so that standard processes are understood and undertaken by all team members.

2. Identify 'experts' and their 'voices'. Weinstein ${ }^{[8]}$ defined two types of experts - those who are expert because of what they know (epistemic expertise), and those who are expert because of what they do (performative expertise). Both have a place in CPG teams, and the relative merits of including one or both types should be considered early. What qualifies an individual to be nominated onto a CPG team as an expert remains unclear. Ideally, experts nominated by professional associations or organisations should be spokespeople for constituents, representing the collective rather than an individual view. The added value of an expert credibly presenting the 'voice' of an organisation is that this should assist with CPG endorsement and implementation.

3. Identify a CPG team leader. Who chairs the CPG team is a critical decision, as the chair is responsible for the efficient and unbiased production of a CPG (World Health Organization (WHO) ${ }^{[9]}$ ). The chair may be identified by the CPG commissioning body, and he/she can be an independent appointment or determined from within the CPG team. He/she should be credible as a leader, and should have a sound understanding of CPG development, general knowledge of the CPG subject, and ideally CPG writing experience. $\mathrm{He} / \mathrm{she}$ should have experience in efficient team management and resolution of conflicts. The WHO also recommends the appointment of a vice-chair. ${ }^{[9]}$

4. Determine and declare conflicts of interest (COIs). COIs arise when an individual's private interests influence (or are perceived by others to influence) a public duty. When writing CPGs, COIs could influence which evidence is supported, which contexts are considered, or whether and how representative constituent feedback is obtained. Guidance regarding COI definitions, declaration and management is provided by the International Committee of Medical Journal Editors (http://www.icmje.org) ${ }^{[10]}$ and the American Thoracic Society Policy for Management of Financial Conflicts of Interest in the Development of ATS Clinical Practice Guidelines. ${ }^{[11]}$ COIs should be determined when the CPG team is first convened and then reassessed regularly, as team members' affiliations and activities may change over time.

5. Determine CPG team terms of reference. Terms of reference help CPG teams to clarify roles, responsibilities and workloads, including setting realistic time frames for obtaining constituent feedback.

6. Establish CPG time frames and tailored capacity development. Many CPG team members work in voluntary capacities. Establishing clear time frames for activities occurring throughout the lifetime of the CPG allows team members to plan ahead. CPG team members often need to learn skills 'on the job', so it is important that training is provided and that team members' activities are monitored, so that they do not 'burn out' through poorly managed processes. ${ }^{[12]}$

7. Establish consensus. It is important that CPG team members agree on an equitable, respectful, efficient consensus process. There are established options for consensus that can be applied by CPG teams. ${ }^{[1]}$ The CPG group may decide that it requires unanimity, or it may allow one or two dissenters whose contrary position is noted in minutes. A majority ruling may require a super-majority $(55-90 \%)$ or a simple majority $(>50 \%)$. If there is divided opinion, the CPG team may accept rulings from the CPG team leader, or from an independent dispute resolution panel.

\section{Conclusion}

Writing CPGs can be time-consuming and expensive. Efforts therefore need to be underpinned by efficient, respectful and agreed processes. The integrity of CPG teams and activities should not be compromised by poor team composition or processes. Justifying CPG team membership, declaring COIs, identifying efficient ways of hearing constituent 'voices', defining and time-lining team tasks and roles, providing necessary training, and respecting individuals' efforts and time should ensure that CPG team members enjoy their experiences. This will contribute to growing CPG expertise in SA and beyond.

\section{Karen Grimmer}

International Centre for Allied Health Evidence, City East Campus, University of South Australia, Adelaide, Australia, and Department of Physiotherapy, Faculty of Medicine and Health Sciences, Stellenbosch University, Tygerberg, Cape Town, South Africa

\section{Janine Margarita Dizon}

Centre for Evidence-Based Health Care, Faculty of Medicine and Health Sciences, Stellenbosch University, Tygerberg, Cape Town, South Africa, and Center for Health Research and Movement Science, University of Santo Tomas, Manila, Philippines

\section{Quinette Louw}

Department of Physiotherapy and Centre for Evidence-Based Health Care, Faculty of Medicine and Health Sciences, Stellenbosch University, Tygerberg, Cape Town, South Africa 


\section{Tamara Kredo}

Cochrane South Africa, South African Medical Research Council, Cape Town, South Africa

\section{Taryn Young}

Centre for Evidence-Based Health Care, Faculty of Medicine and Health Sciences, Stellenbosch University, Tygerberg, Cape Town, South Africa, and Cochrane South Africa, South African Medical Research Council, Cape Town

\section{Shingai Machingaidze}

Cochrane South Africa, South African Medical Research Council, Cape Town, South Africa, and European and Developing Countries Clinical Trials Partnership (EDCTP), Cape Town

\section{Corresponding author: K Grimmer (karen.grimmer@unisa.edu.au)}

1. Schünemann HJ, Wiercioch W, Etxeandia I, et al. Guidelines 2.0: Systematic development of a comprehensive checklist for a succesful guideline enterprise Can Med Assoc J 2014:186(3):E123-E142. DOI: $10.1503 / \mathrm{cmaj} .131237$
2. Brouwers MC, Kho ME, Browman GP, et al. Development of the AGREE II, part 1: Performance, usefulness and areas for improvement. Can Med Assoc J 2010a:182(10):1045-1052. DOI:10.1503/ cmaj.091714

3. Brouwers MC, Kho ME, Browman GP, et al. Development of the AGREE II, part 2: Assessment of validity of items and tools to support application. Can Med Assoc J 2010b;182(10):E472-E478. DOI:10.1503/cmaj.091716

4. Hillier S, Grimmer-Somers K, Merlin T, et al. FORM: An Australian method for grading recommendations in evidence-based clinical guidelines. BMC Methodol 2011;11:23. DOI:10.1186/1471-2288-11-23 5. Guyatt GH, Oxman AD, Schünemann HJ, Tugwell P, Knottnerus A. GRADE guidelines: A new series of articles in the Journal of Clinical Epidemiology. J Clin Epidemiol 2011;64(4):380-382. DOI:10.1016/j. jclinepi.2010.09.011

6. Machingaidze S, Kredo T Young T, Louw Q, Grimmer K. South African Guidelines Excellence (SAGE): Clinical practice guidelines - quality and credibility. S Afr Med J 2015;105(9):743-745. DOI:10.7196/ SAMJnew.7697

7. Kredo T, Machingaidze S, Young T, Louw Q, Grimmer K. South African Guidelines Excellence (SAGE): What's in a name? S Afr Med J 2015;106(1):18-20. DOI:10.7196/SAMJ.2016.v106i1.10286 8. Weinstein BD. What is an expert? Theor Med 1993;14(1):57-73. DOI:10.1007/BF00993988

9. World Health Organization. WHO Handbook for Guideline Development. Geneva: WHO, 2011. http:// 9. World Health Organization. WHO Handbook for Guideline Development. Geneva: WHO, 2011. h
apps.who.int/iris/bitstream/10665/75146/1/9789241548441_eng.pdf (accessed 11 February 2016).

10. International Committee of Medical Journal Editors. http://www.icmje.org/conflicts-of-interest/ (accessed 6 January 2016).

11. American Thoracic Society Policy for Management of Financial Conflicts of Interest in the Development of ATS Clinical Practice Guidelines as Approved by the Board of Directors, January 2015. https://www. thoracic.org/statements/document-development/resources/cpg-specific-coi-policy.pdf (accessed 29 February 2016).

12. Luban R. Keeping the Fire: From Burnout to Balance. Ruth Luban Audio \& Books, 1996.

S Afr Med J 2016;106(5):440-441. DOI:10.7196/SAMJ.2016.v106i5.10770 